\title{
Quality of Hospice Care for Patients with Dementia
}

\author{
Jennifer S. Albrecht, PhD' ${ }^{1}$, Ann L. Gruber-Baldini, PhD ${ }^{1}$, Erik K. Fromme, MD²,3, Jessina C. \\ McGregor, PhD ${ }^{4}$, David S.H. Lee, PharmD, $\mathrm{PhD}^{4}$, and Jon P. Furuno, PhD 4 \\ ${ }^{1}$ Department of Pharmaceutical Health Services Research, School of Pharmacy, University of \\ Maryland, Baltimore, MD \\ ${ }^{2}$ Oregon Health \& Science University, Knight Cancer Institute, Division of Hematology and \\ Medical Oncology, Portland, OR \\ ${ }^{3}$ Oregon Health \& Science University, Center for Ethics in Healthcare, Portland, OR \\ ${ }^{4}$ Department of Pharmacy Practice, Oregon State University/Oregon Health \& Science University \\ College of Pharmacy, Portland, OR
}

\begin{abstract}
Background-Patients with dementia constitute an increasing proportion of hospice enrollees, yet little is known about the quality of hospice care for this population.

Objectives-To quantify differences in quality of care measures between hospice patients with and without dementia.

Study Design-Cross-sectional analysis of data from the 2007 National Home and Hospice Care Survey

Participants-4,711 discharges from hospice care

Measurements-A primary diagnosis of dementia at discharge was defined by ICD-9 codes: 290.0-290.4x, 294.0, 294.1, 294.8, 331.0-331.2, 331.7, and 331.8. Quality of care measures included enrollment into hospice in the last three days of life, receiving tube feeding, depression, receiving antibiotics, lack of advanced directive or do not resuscitate order, zstage II pressure ulcers, emergent care, lack of continuity of residence and a report of pain at last assessment.
\end{abstract}

Results-450 (9.5\%) discharges had a primary diagnosis of dementia. In multivariable analysis, patients with dementia were more likely to receive tube feeding [OR 2.6 (95\% CI: 1.4, 4.5)] and to have greater continuity of residence [OR 1.8 (95\% CI: 1.1,3.0)] compared to other hospice patients. They were less likely to have a report of pain at last assessment [OR 0.6 (95\% CI: 0.3, $0.9)]$.

Conclusions-The majority of quality of care measures examined in this study did not differ between hospice patients with and without dementia. Use of tube feeding in hospice care and

Corresponding Author: Jennifer S. Albrecht, PhD, Pharmaceutical Health Services Research, School of Pharmacy, University of Maryland, 220 Arch Street, 12th floor, Room 01-234, Baltimore, MD 21201, Phone: (410) 706-5451, Fax: (410) 706-5394,

jalbrecht@rx.umaryland.edu. Alternate Corresponding Author: Jon P. Furuno, PhD, OSU/OHSU College of Pharmacy, Department of Pharmacy Practice, 3303 SW Bond Ave., Mail Code: CH12C, Portland, OR 97239, Telephone: (503) 418-9361, Fax: (503) 494-8797 furuno@ohsu.edu. 
methods of pain assessment and treatment in patients with dementia should be considered as potential quality of care measures.

\section{Keywords}

dementia; hospice and palliative medicine; quality of care; NHHCS

\section{Introduction}

Hospice was originally conceived for patients with cancer, yet patients with Alzheimer's disease and other dementias (hereafter referred to as dementia) form an increasing proportion of those enrolling in hospice care. ${ }^{1,2}$ Caring for patients with dementia poses significant challenges to hospice providers because their needs may differ from those of other hospice patients and they may be less able to communicate their symptoms or provide information on symptom improvement following treatment. ${ }^{3}$

Assessing the quality of hospice care provided to patients with dementia is essential to ensure the highest level of care in this patient population. Nonetheless, in its 2011 report to Congress, the Medicare Payment Advisory Commission noted that research on the quality of hospice care, especially for patients with dementia, is lacking despite the mandate for public reporting of quality data. ${ }^{2}$

It is unclear how well existing quality measures for end-of-life care address the needs of patients with dementia. The National Consensus Project for Quality Palliative Care (NCP) proposed eight domains for high quality care at the end of life and developed clinical guidelines to address these domains. ${ }^{4}$ The guidelines call for the regular assessment and management of pain and non-pain symptoms, but do not mention eating problems, which are common among patients with advanced dementia and often lead feeding tube use in these patients. ${ }^{4,5}$ Furthermore, because patients with dementia have difficulty reporting symptoms, pain assessment and management is often more challenging.

The objective of this study was to quantify differences in quality measures, based upon domains proposed by the NCP and previous research, between hospice patients with and without dementia using data from the 2007 National Home and Hospice Care Survey (NHHCS), a nationally-representative sample of hospice patients. ${ }^{4,6-11}$ Differences in quality measures between patients with and without dementia may highlight areas where current quality measures aren't sufficient to ensure the highest quality end of life care for patients with dementia. We also sought to understand how agency and facility characteristics may impact differences between hospice patients with and without dementia with regard to these quality measures. To our knowledge this is the first study to compare quality measures between patients with and without dementia who are receiving hospice care in a national sample. 


\section{Methods}

\section{Data Source}

The 2007 NHHCS was conducted by the Centers for Disease Control and Prevention and the National Center for Health Statistics. It is a nationally-representative sample of U.S. home health and hospice agencies which was designed to provide descriptive information on the agencies along with their staff, services, and patients. ${ }^{12}$ The survey used a stratified twostage probability sample design. In the first stage, 1,545 agencies were systematically and randomly sampled with probability proportional to agency size. In the second stage, up to 10 hospice discharges per hospice agency, and a combination of up to 10 current home health patients and hospice discharges per mixed agency were randomly selected. Hospice discharges were defined as patients who were discharged (alive or deceased) from a hospice agency during the 3-month period beginning 4 months before the agency interview. ${ }^{12}$ Patient data were collected through in-person interviews with the hospice agency directors and designated staff in consultation with patients' medical records. Neither patients nor family members were interviewed. In total, 4,733 interviews were performed. Patient data included demographic variables, clinical characteristics, and hospice facility characteristics. Each patient received only one current primary diagnosis code which referred to the patient's primary diagnosis at discharge.

\section{Identification of Hospice Quality of Care Measures for Patients with Dementia}

The NCP domains for high quality care at the end of life encompass structure and processes of care, physical aspects of care, psychological and psychiatric aspects of care, social aspects of care, spiritual, religious and existential aspects of care, cultural aspects of care, care of the imminently dying patient, and ethical and legal aspects of care. ${ }^{4}$ In this study we choose to focus primarily on physical, psychological, and ethical aspects of care. Therefore, based on the NCP guidelines, the following measures were identified in the 2007 NHHCS dataset: report of depression, a report of pain at the last assessment in hospice care, presence of standing orders for pain medication, presence of a 'do not resuscitate' (DNR) order, and presence of any advanced directive.

We also sought to include quality of care measures that were important in patients with dementia. Therefore we identified previously published measures associated with poorer quality of care for patients with dementia, particularly those identified for patients at the end of life. These included receiving tube feeding, use of emergent services, presence of a stage II or greater pressure ulcer, enrollment in hospice care in the last 3 days of life, continuity of residence, and antibiotic utilization. ${ }^{8-11}$

\section{Variable Definitions}

We defined a primary diagnosis of dementia at discharge as ICD-9 codes: 290.0, 290.1x, 290.2x, 290.3, 290.4x, 294.0, 294.1, 294.8, 331.0, 331.1x, 331.2, 331.7, and 331.8.11-13 All other current primary diagnoses at discharge were grouped as 'other'. ${ }^{13-15}$

Tube feeding was defined as the use of any type of tube feeding or total parenteral nutrition at any time during hospice care. Pressure ulcers were staged according to the highest stage 
of any current or past pressure ulcer while in hospice care. Use of emergent services was defined as emergency care at a hospital, doctor's office or outpatient clinic. Continuity of residence from when first and last received hospice care was either 'same place' or 'different place'. Enrollment in hospice in the last 3 days of life was only examined among patients who were deceased at discharge. Presence of pain during the patient's last assessment was recorded as a dichotomous variable. Pain measurement tools included 0-5 and $0-10$ scales, a word scale (mild, moderate, severe), $0-10$ and $0-5$ face scales, the Face, Legs, Activity, Cry, Consolability (FLACC) scale, observation of patient, and patient's/ family's description. The data did not indicate cut points for the presence or absence of pain.

The names of up to 25 medications that the patient received in the 7 days prior to and on the day of death or discharge were recorded in the NHHCS data set and categorized using the Lexicon Plus ${ }^{\circledR}$ (Cerner Multum, Inc., Denver, CO). Using the Multum categories, we created a variable for receiving any antibiotic in the last seven days of hospice care.

\section{Data Analysis}

Data analysis was performed using SAS version 9.2 (SAS Institute Inc., Cary, NC). All estimates were weighted to account for the survey's complex sampling design but frequencies were presented un-weighted so that the underlying data distribution was evident. Descriptive statistics were calculated for patients' demographics (e.g., age, sex, race/ ethnicity, marital status) and patients' characteristics relating to hospice care quality (e.g., enrollment in hospice in last 3 days of life, tube feeding, presence of an advanced directive or DNR order, pressure ulcer stage, use of emergent care, receiving antibiotics, continuity of residence, and pain reported at last assessment). Comparisons between patients with dementia and all other patients were conducted using chi-square tests for categorical variables and t-tests for continuous variables. All tests were assessed for statistical significance at the $\mathrm{p}<0.05$ level.

To examine whether observed differences in quality of care were explained by the older age of dementia patients or facility level characteristics, a separate logistic regression equation was constructed for each quality of care measure. We considered the following variables for inclusion in our models: dementia, age at discharge, location of hospice care (private home, residential care place, nursing home, or other (included agency inpatient and hospital)), agency type (mixed or hospice only), profit status (for profit or non-profit), and metropolitan area (metropolitan: $\geq 50,000$ population, micropolitan: 10,000 - 49,999 population, and rural: $<10,000$ population). When final models were obtained using the process outlined above, effect modifiers identified using the Breslow-Day test (with a p-value of 0.05 or less) and their main effects were examined. The Breslow-Day test was performed on unweighted data. Odds ratios (OR) and corresponding 95\% confidence intervals (95\% CI) were reported.

The institutional review boards (IRBs) at the University of Maryland, Baltimore and Oregon State University determined that this study was exempt from IRB oversight due to the use of publically-available, fully de-identified data. 


\section{Results}

There were 4,733 hospice discharges included in the 2007 NHHCS, of which $450(10 \%)$ had a current primary diagnosis of dementia (Table 1). Of these, 35\% had Alzheimer's disease (ICD-9 code 331.0), 56\% had other persistent mental disorders due to conditions classified elsewhere (ICD-9 code 294.8) and the remainder had other dementias. Twenty-two patients lacked a current primary diagnosis and were excluded from the study, leaving 4,261 patients with a diagnosis other than dementia who were included in our analyses. Twenty-one percent of patients with dementia were discharged alive from hospice, compared to $15 \%$ of all other patients $(\mathrm{p}=0.02)$.

Patients with a primary current diagnosis of dementia differed significantly from other patients on both demographic and facility characteristics. Compared to all other patients, patients with dementia were older, with a mean age (standard deviation) of $85( \pm 0.7)$ years vs. $77( \pm 0.4)$ years $(\mathrm{p}<0.001)$ and more likely to be widowed $(51 \%$ vs. $37 \%, \mathrm{p}=0.002)$. Patients with dementia were also more likely to receive hospice care in a nursing facility ( $54 \%$ vs. $20 \%$, p $<0.001$ ), and only $24 \%$ received care in a private home. Furthermore, patients with dementia were more likely to be served by for-profit hospices (46\% vs. $29 \%$, $\mathrm{p}<0.001$ ) and to receive care in larger metropolitan areas ( $90 \%$ vs. $87 \%, \mathrm{p}=0.02)$. They had a longer hospice stay, with a median (interquartile range) of 41 days $(6,170)$ vs. 15 days $(4$, $54)(\mathrm{p}<0.001)$ and were much more likely to have a hospice stay of more than 180 days $(23 \%$ vs. $9 \%, \mathrm{p}<0.001)$.

Patients with dementia differed significantly from other hospice patients on several quality of care measures (Table 2). They were significantly more likely to receive tube-feeding (10\% vs. $4 \%$, p $<0.001)$. Four percent of patients with dementia (compared with $5 \%$ of other hospice patients) had a feeding restrictions advanced directive. Among patients with dementia, receipt of tube feeding did not differ between those with a feeding restrictions advanced directive and those without (11\% vs. 10\%, $\mathrm{p}=0.9)$. Patients with dementia were also more likely to have a DNR order ( $88 \%$ vs. $81 \%, \mathrm{p}=0.02)$ and have greater continuity of residence $(90 \%$ vs. $83 \%, \mathrm{p}=0.006)$ compared to other hospice patients.

Patients with dementia were less likely to enroll in hospice care in the last three days of life ( $16 \%$ vs. $26 \%, \mathrm{p}=0.05$ ). Patients with dementia were also less likely to have a report of pain at last assessment ( $19 \%$ vs. $31 \%, \mathrm{p}=0.006$ ) or to have standing orders for pain medication (56\% vs. $68 \%, \mathrm{p}=0.01$ ) compared to other hospice patients.

Among patients with a report of pain at last assessment, there was a non-significant difference in the presence of standing orders for pain medication between patients with and without dementia ( $78 \%$ vs. $72 \%, \mathrm{p}=0.5$ ). However, among patients with no report of pain at last assessment, patients with dementia had fewer standing orders for pain medication (48\% vs. $65 \%, \mathrm{p}<0.01)$. Very few patients $(2 \%)$ had an advanced directive restricting medication; therefore this was not examined in our analyses.

The presence of pain was not assessed in all hospice patients, however patients with dementia were no more likely to have the report marked as 'inapplicable/not assessed' $(13.5 \%$ vs. $13.7 \%, \mathrm{p}=1.0)$ or 'don't know' ( $3.3 \%$ vs. $7.2 \%, \mathrm{p}=0.05)$ compared with other 
hospice patients. In patients with dementia, observation of the patient was used most often to assess pain at the last visit (54\%), followed by a 0-10 numeric scale (19\%), and the FLACC scale $(14 \%)$. No other significant unadjusted differences in quality of care measures were observed.

In multivariable logistic regression models, dementia remained a significant predictor of tube feeding [OR 2.6 (95\% CI: 1.4, 4.5)], no report of pain at last assessment [OR 0.6 (95\% CI: 0.3, 0.9)], and continuity of residence [OR 1.8 (95\% CI: 1.1, 3.0)](Table 3). No effect modification was observed. See Table 3 for covariates included in each logistic regression model.

\section{Discussion}

Overall, we observed few differences in quality of care measures between patients with and without dementia in this nationally-representative sample of hospice patients. Patients with dementia were more likely to have greater continuity of residence, a marker of better end-oflife care. However, patients with dementia were also more likely to receive tube feeding and less likely to have a report of pain at last assessment compared to other hospice patients.

Tube feeding among patients with dementia was relatively common. The decision to institute tube feeding is highly emotional and often made by family members in conjunction with care providers. Nevertheless, there is little evidence that tube feeding is beneficial in patients with advanced dementia and there are ethical concerns that it could increase patient burden, especially regarding the use of restraints to prevent self-extubation. ${ }^{10} \mathrm{~A}$ Cochrane review reported no evidence of increased survival, better nutrition, decreased pressure sores or decreased risk of aspiration pneumonia among patients with advanced dementia receiving tube feeding. ${ }^{16}$ Given the natural history of dementia, hospices who enroll patients with advanced dementia should discuss feeding tubes with surrogates; attempt to correct misunderstandings about effectiveness in this patient population, and document feeding tube preferences in an advanced directive or a physician order for life sustaining treatment (POLST) paradigm form. In this sample, only $4 \%$ of patients with dementia had a feeding restrictions advanced directive. This study suggests that tube feeding be considered as a potential quality measure for hospice patients with dementia.

Patients with dementia had fewer reports of pain at their last assessment than other hospice patients. While less pain is a goal of palliative care, fewer reports of pain may also indicate inadequate measurement of pain. The NCP Clinical Practice Guidelines call for the regular assessment and treatment of symptoms, including pain, using validated methods. ${ }^{4}$ Assessment of pain in patients with severe dementia is complicated by their inability to accurately self-report, but there are validated behavioral observational scales recommended for use in patients with severe cognitive impairment. ${ }^{17-19}$ In these data, observational methods to assess pain were used only half of the time, and the specific methods used were not well described. Given that pain in patients with dementia is often under-assessed and undertreated, it is important to ensure that validated methods of assessing pain are utilized. ${ }^{20}$ Therefore; a second potential quality of care measure for hospice patients with dementia 
might include the use of validated methods to assess pain and/or standing orders for pain medication.

This study had several limitations. The structure and content of the NHHCS data limited the comparisons we could make and we were unable to link to agency level data that may have provided information about whether these quality measures reflect hospice agency performance. Furthermore, the NHHCS does not provide information on quality of life in patients with dementia nor does it provide any information on patient or family satisfaction with care.

Still, this is the first study, to our knowledge, to examine these quality of care measures in a national sample of hospice patients with dementia and to compare these measures between patients with and without dementia. The majority of quality of care measures examined in this study did not differ between hospice patients with and without dementia. This suggests that despite their differences from other hospice patients, patients with dementia are generally receiving the same quality of hospice care. Nevertheless, hospice patients with dementia differed from other hospice patients on two quality of care measures that may indicate poorer quality of care. Specifically, use of tube feeding in hospice care and methods of pain assessment and treatment in patients with dementia should be considered as potential quality of care measures. Future studies should focus on the associations between quality of care measures and important hospice outcomes including quality of life and patient and family satisfaction with hospice care.

\section{Acknowledgments}

Financial Support: This work was supported by Agency for Healthcare Research and Quality grant R36HS021068-01 (J.S.A), National Institutes of Health grants T32AG000262-14 (J.S.A.), R03HS020970 (J.C.M.), K07CA109511 (E.K.F..), and K01AI071015-05 (J.P.F.), and National Heart, Lung, \& Blood Institute grant R01 HL085706 (A.L.G.).

\section{References}

1. Medicare Payment Advisory Commission. Report to the Congress: Medicare payment policy. Washington, DC: MedPAC; 2010. (online). Available at: http://www.medpac.gov/documents/ Mar10_EntireReport.pdf. [Accessed June 8, 2012]

2. Medicare Payment Advisory Commission. Report to the Congress: Medicare Payment Policy, Chapter 11. Hospice. Washington, DC: MedPac; 20001. 2011 (online). Available at: http:// www.medpac.gov/documents/Mar11_EntireReport.pdf. [Accessed June 8, 2012]

3. Sachs G, Shega J, Cox-Hayley D. Barriers to excellent end-of-life care for patients with dementia. J Gen Intern Med. 2004; 19:1057-1063. [PubMed: 15482560]

4. [Accessed June 8, 2012] National Consensus Project for Quality Palliative Care: Clinical Practice Guidelines for Quality Palliative Care, Second Edition. 2009. (online). Available at: www.nationalconsensusproject.org.

5. Mitchell SL, Teno JM, Kiely DK, et al. The Clinical Course of Advanced Dementia. J Am Geriatr Soc. 2009; 361(16):1529-1538.

6. Schenck A, Rokoske F, Durham D, et al. The PEACE Project: identification of quality measures for hospice and palliative care. J Palliat Med. 2010; 13:1451-1459. [PubMed: 21155640]

7. Teno JM. Measuring End-of-Life Care Outcomes Retrospectively. Journal of Palliative Medicine. 2005; 8:S42-S48. [PubMed: 16499468]

8. Mitchell S, Kiely D, Miller S, et al. Hospice care for patients with dementia. J Pain Symptom Manage. 2007; 34:7-16. [PubMed: 17509813] 
9. Gozalo P, Teno J, Mitchell S, et al. End-of-life transitions among nursing home residents with cognitive issues. N Engl J Med. 2011; 365:1212-1221. [PubMed: 21991894]

10. Teno J, Mitchell S, Kuo S, et al. Decision-making and outcomes of feeding tube insertion: a fivestate study. J Am Geriatr Soc. 2011; 59:881-886. [PubMed: 21539524]

11. Aminoff B, Adunsky A. Dying dementia patients: too much suffering, too little palliation. The American journal of hospice palliative care. 2005; 22:344-348. [PubMed: 16225356]

12. [Accessed June 6, 2011] Technical Notes for the 2007 NHHCS Medication Public-use File (online). Available at: http://www.cdc.gov/nchs/data/nhhcsd/

NHHCS_NHHAS_web_documentation.pdf.

13. Martin BC, Ricci JF, Kotzan JA, et al. The net cost of Alzheimer disease and related dementia: a population-based study of Georgia Medicaid recipients. Alzheimer Dis Assoc Disord. 2000; 14:151-159. [PubMed: 10994656]

14. Taylor D, Fillenbaum G, Ezell M. The accuracy of medicare claims data in identifying Alzheimer's disease. J Clin Epidemiol. 2002; 55:929-937. [PubMed: 12393082]

15. Centers for Medicare \& Medicaid Services. [Accessed April 3, 2012] Chronic Conditions Warehouse (online). Available at: http://www.ccwdata.org/chronic-conditions/index.htm.

16. Sampson E, Candy B, Jones L. Enteral tube feeding for older people with advanced dementia. Cochrane database of systematic reviews. 2009:CD007209-CD007209. [PubMed: 19370678]

17. Kaasalainen S. Pain assessment in older adults with dementia: using behavioral observation methods in clinical practice. J Gerontol Nurs. 2007; 33:6-10. [PubMed: 17598622]

18. Lukas A, Schuler M, Fischer TW, et al. Pain and dementia: A diagnostic challenge. Zeitschrift für Gerontologie und Geriatrie. 2012; 45:45-49. [PubMed: 22278006]

19. Zwakhalen SMG, Hamers JPH, Abu-Saad H, et al. Pain in elderly people with severe dementia: a systematic review of behavioral pain assessment tools. BMC Geriatrics. 2006; 6:3-3. [PubMed: 16441889]

20. Morrison RS, Siu AL. A comparison of pain and its treatment in advanced dementia and cognitively intact patients with hip fracture. J Pain Symptom Manage. 2000; 19:240-248. [PubMed: 10799790] 
Table 1

Characteristics of Hospice Discharges in 2007 by Dementia Status, $\mathrm{N}=4,733^{a}$

\begin{tabular}{|c|c|c|c|c|}
\hline Characteristic & $\underset{\mathrm{N}=4,733}{\text { All }}$ & $\begin{array}{l}\text { Patients with } \\
\text { Dementia } \\
\mathrm{N}=\mathbf{4 5 0}\end{array}$ & $\begin{array}{l}\text { All Other } \\
\text { Patients } \\
\mathrm{N}=4,261\end{array}$ & P-Value $b$ \\
\hline Age in years, mean (sd) & $78( \pm 0.3)$ & $85( \pm 0.7)$ & $77( \pm 0.4)$ & $<0.001$ \\
\hline Days Received Hospice Care, Median $\left(\mathrm{IQR}^{c}\right)$ & $16(4,61)$ & $41(6,170)$ & $15(4,54)$ & $<0.001$ \\
\hline Length of Hospice Care >180 days, n(\%) & $549(10)$ & $108(24)$ & $441(9)$ & $<0.001$ \\
\hline $\begin{array}{l}\text { Sex, } \mathrm{n}(\%) \\
\text { Female } \\
\text { Male }\end{array}$ & $\begin{array}{l}2,602(55) \\
2,109(45)\end{array}$ & $\begin{array}{l}295(61) \\
155(39)\end{array}$ & $\begin{array}{l}2,307 \text { (54) } \\
1,954(46)\end{array}$ & 0.2 \\
\hline $\begin{array}{l}\text { Race, } \mathrm{n}(\%) \\
\text { Hispanic } \\
\text { White, non-Hispanic } \\
\text { Black, non-Hispanic } \\
\text { Other }\end{array}$ & $\begin{array}{c}147(4) \\
4,087(86) \\
310(8) \\
79(2)\end{array}$ & $\begin{array}{c}12(3) \\
375(87) \\
46(9) \\
9(1)\end{array}$ & $\begin{array}{l}135(4) \\
3,712(87) \\
264(7) \\
71(2)\end{array}$ & 0.5 \\
\hline $\begin{array}{l}\text { Marital Status, } \mathrm{n}(\%) \\
\text { Married } \\
\text { Widowed } \\
\text { Divorced } \\
\text { Other }\end{array}$ & $\begin{array}{l}2,010(42) \\
1,840(38) \\
338(7) \\
523(13)\end{array}$ & $\begin{array}{c}149(38) \\
233(51) \\
15(1) \\
53(10)\end{array}$ & $\begin{array}{c}1,861(43) \\
1,607(37) \\
323(7) \\
470(13)\end{array}$ & 0.002 \\
\hline $\begin{array}{l}\text { Location of Hospice Care, } \mathrm{n}(\%) \\
\text { Private Home } \\
\text { Residential Care Place } \\
\text { Nursing Facility } \\
\text { Other }\end{array}$ & $\begin{array}{l}2,517(49) \\
253(6) \\
1,082(23) \\
848(22)\end{array}$ & $\begin{array}{l}136(24) \\
49(13) \\
217(54) \\
46(10)\end{array}$ & $\begin{array}{l}2,381(52) \\
204(5) \\
865(20) \\
802(24)\end{array}$ & $<0.001$ \\
\hline Deceased at discharge, $\mathrm{n}(\%)$ & $3,867(85)$ & $325(79)$ & $3,542(85)$ & 0.02 \\
\hline $\begin{array}{l}\text { Agency Type, } \mathrm{n}(\%) \\
\text { Hospice Only } \\
\text { Mixed Hospice/Home Health }\end{array}$ & $\begin{array}{l}3,230(69) \\
1,481(32)\end{array}$ & $\begin{array}{l}344(75) \\
106(25)\end{array}$ & $\begin{array}{l}2,886(67) \\
1,375(33)\end{array}$ & 0.1 \\
\hline $\begin{array}{l}\text { Profit Status, } \mathrm{n}(\%) \\
\text { For-Profit } \\
\text { Non-Profit/Government }\end{array}$ & $\begin{array}{l}1,094(31) \\
3,617 \text { (69) }\end{array}$ & $\begin{array}{l}144(46) \\
306(54)\end{array}$ & $\begin{array}{c}950(29) \\
3,311(71)\end{array}$ & $<0.001$ \\
\hline $\begin{array}{l}\text { Metropolitan Region, } \mathrm{n}(\%) \\
>50,000 \\
10,000-49,999 \\
<10,000\end{array}$ & $\begin{array}{c}1,731(87) \\
1,749(9) \\
1,231(4)\end{array}$ & $\begin{array}{l}172(90) \\
176(7) \\
102(2)\end{array}$ & $\begin{array}{l}1,559(87) \\
1,573(9) \\
1,129(4)\end{array}$ & 0.02 \\
\hline
\end{tabular}

${ }^{a}$ Weighted percentages

${ }^{b}$ Chi-square for categorical variables, T-test for continuous variables

$c_{\text {IQR: Interquartile range }}$ 
Table 2

Hospice Care Quality Measures by Dementia Status, N=4,733 ${ }^{a}$

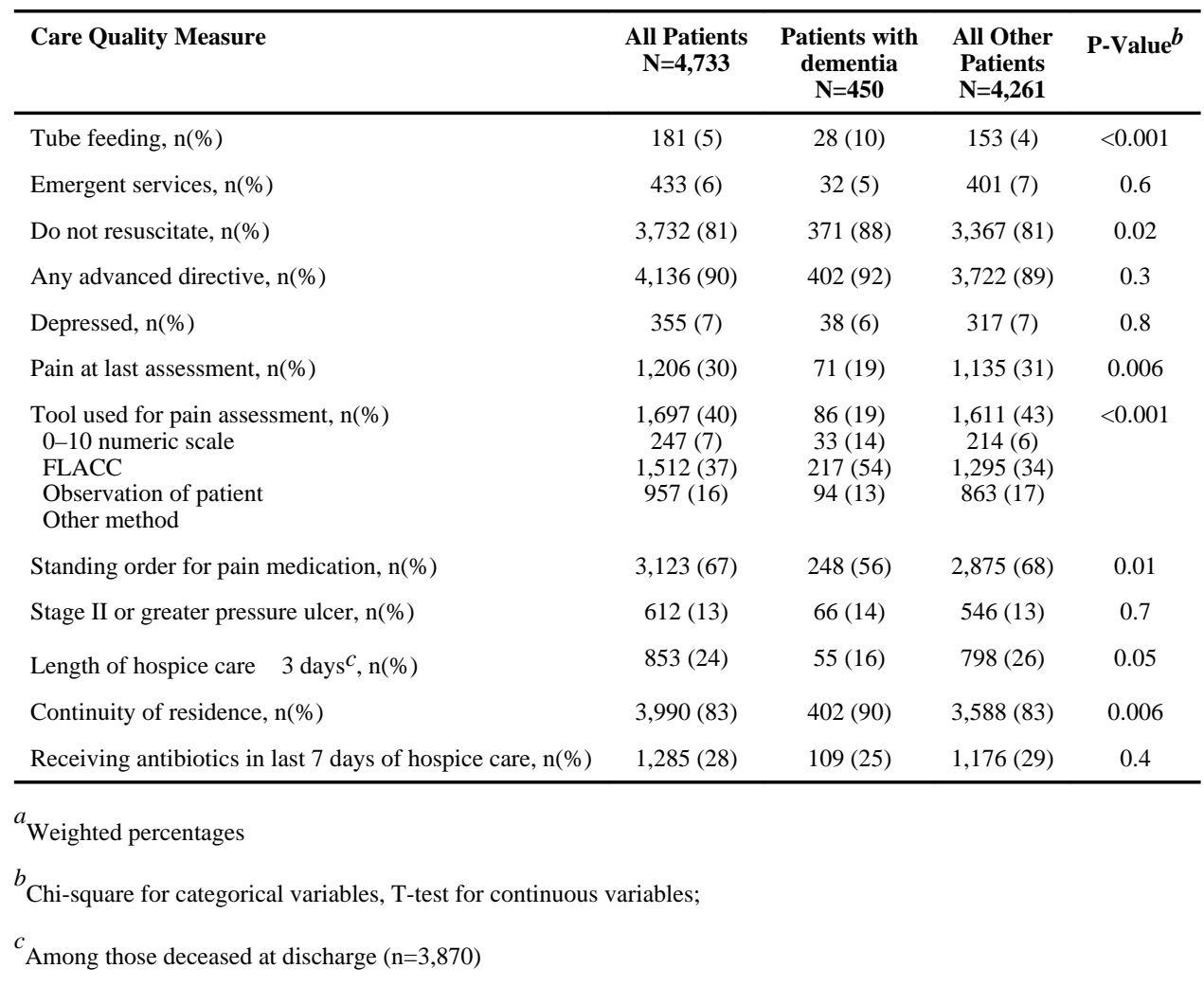


Table 3

Adjusted and Unadjusted Odds Ratios of Dementia Regressed on Care Quality Measures, n=4,711

\begin{tabular}{lcc}
\hline Care Quality Indicator & Unadjusted & Adjusted \\
\hline Tube feeding & $2.6(1.6,4.4)$ & $2.6(1.4,4.5)^{a}$ \\
Emergent services & $0.8(0.4,1.7)$ & $0.9(0.4,1.9)^{b}$ \\
Do not resuscitate & $1.8(1.1,2.9)$ & $1.4(0.6,2.3)^{c}$ \\
Any advanced directive & $1.4(0.7,2.7)$ & $0.9(0.4,2.0)^{d}$ \\
Depressed & $0.9(0.4,2.1)$ & $0.8(0.4,2.0)^{e}$ \\
Pain at last assessment & $0.5(0.3,0.8)$ & $0.6(0.3,0.9)^{f}$ \\
Standing order for pain medication & $0.6(0.4,0.9)$ & $0.7(0.5,1.0)^{g}$ \\
Stage II or greater pressure ulcer & $1.1(0.7,1.7)$ & $1.0(0.6,1.6)^{h}$ \\
Length of hospice care $\leq 3$ days & $0.6(0.4,1.0)$ & $0.7(0.41 .1)^{i}$ \\
Continuity of residence & $1.8(1.1,2.9)$ & $1.8(1.1,3.0)^{j}$ \\
Receiving antibiotics in last 7 days of hospice care & $0.8(0.5,1.3)$ & $0.9(0.6,1.4)^{k}$ \\
\hline
\end{tabular}

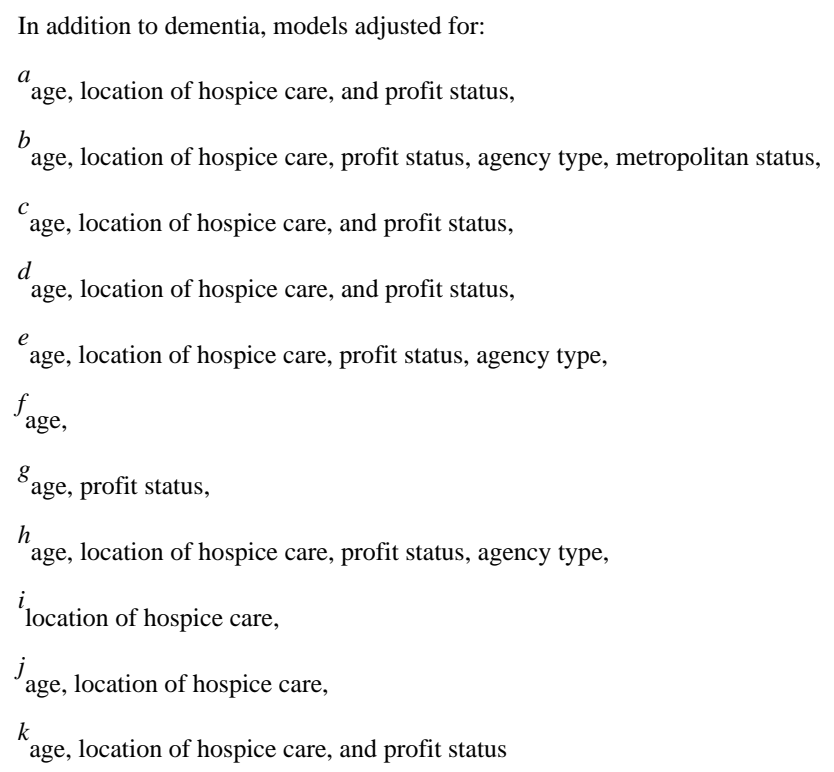

